\title{
Aspectos imunológicos da infecção pelo vírus do papiloma humano (HPV)
}

\section{Immunological aspects of human papiloma virus (HPV) infection}

\author{
Adeline Limberger'; Caio Ferreira de Oliveira ${ }^{2}$; Mab Pereira Correa ${ }^{3}$; Thamile \\ Luciane Reus ${ }^{4}$; Julie Massayo Maeda Oda ${ }^{5}$; Natália Ketelut Carneiro ${ }^{6}$; Maria \\ Angelica Ehara Watanabe ${ }^{7}$
}

\begin{abstract}
Resumo
O vírus do papiloma humano (HPV-human papiloma virus) pode infectar até $80 \%$ das pessoas, principalmente as sexualmente ativas. O risco e a sintomatologia da infecção são distintos entre os gêneros. Sabe-se que existem mais de 150 sorotipos e estes são agrupados por seu tropismo. Embora a maioria das infecções siga um curso benigno, a infecção persistente por certos sorotipos pode levar ao desenvolvimento de câncer. Os sorotipos 16 e 18 estão envolvidos com uma forma grave de lesão, acarretando câncer, principalmente do colo do útero. Os sorotipos 6 e 11 são descritos como causadores de verrugas anogenitais. O vírus, de aproximadamente $8.000 \mathrm{pb}$, se instala na célula e por meio da expressão das oncoproteínas E6 e E7, levando à inibição de proteínas como a p53 e a pRB, importantes na apoptose e na parada do ciclo celular. As vacinas atuais geram imunidade contra os sorotipos 6 , $11,16$ e 18. A vacina pode ser tetravalente (quatro sorotipos: $6,11,16$ e 18$)$ ou bivalente $(16$ e 18$)$. Ambas apresentam proteção cruzada contra a infecção por sorotipos não inclusos nas vacinas, porém não possuem caráter terapêutico. O presente trabalho teve como proposta revisar os avanços sobre a infecção pelo HPV, os aspectos imunológicos e as vacinas profiláticas disponíveis.

Palavras - Chaves: HPV. Vírus do papiloma humano. Vacinas. Mecanismos imunológicos. Câncer de colo de útero.
\end{abstract}

${ }^{1}$ Estudantes do $3^{\circ}$ ano do curso de Biomedicina da Universidade Estadual de Londrina. E-mails: adeline.limberger@gmail.com

${ }^{2}$ Estudantes do $3^{\circ}$ ano do curso de Biomedicina da Universidade Estadual de Londrina. E-mails: caioferreira.biomed@gmail.com

${ }^{3}$ Estudantes do $3^{\circ}$ ano do curso de Biomedicina da Universidade Estadual de Londrina. E-mails: mabiiic@gmail.com

${ }^{4}$ Estudantes do $3^{\circ}$ ano do curso de Biomedicina da Universidade Estadual de Londrina. E-mails: thamilelreus@gmail.com

5 Docente do Depto. Ciências Patológicas, Laboratório de Genética Molecular e Imunologia, Universidade Estadual de Londrina, Campus Universitário, Rodovia Celso Garcia Cid (PR 445), 86051-970, Londrina, PR, Brasil. E-mail: julie_massayo@hotmail. com.

${ }^{6}$ Estudante do $4^{\circ}$ ano do curso de Biomedicina da Universidade Estadual de Londrina. E-mail: natketelut@hotmail.com.

7 Docente do Depto. Ciências Patológicas, Laboratório de Genética Molecular e Imunologia, Universidade Estadual de Londrina, Campus Universitário, Rodovia Celso Garcia Cid (PR 445), 86051-970, Londrina, PR, Brasil. E-mail: maewatuel@gmail.com. 


\begin{abstract}
The human papilloma virus (HPV-human papilloma virus) can infect up to $80 \%$ of people, especially sexually active. The risk of infection and symptoms are different between the sexes. It is known that there are over 150 serotypes and these are grouped by their tropism. Although most infections follow a benign course, the persistent infection with certain serotypes may lead to the development of cancer. The serotypes 16 and 18 are involved in a severe form of injury, resulting in cancer, particularly cervical cancer. Serotypes 6 and 11 are described as causes of anogenital warts. The virus, approximately 8.000 $\mathrm{bp}$, it installs itself in the cell and through the expression of oncoproteins E6 and E7 leading to inhibition of proteins such as p53 and pRB, important in apoptosis and cell cycle arrest. Current vaccines generate immunity against serotypes $6,11,16$ and 18 . The vaccine can be tetravalent (four serotypes $6,11,16$ and 18$)$ or bivalent $(16,18)$. Both have cross-protection against infection by serotypes not included in the vaccines, but have no therapeutic character. This study was proposed to review progress on the HPV infection, the immunological aspects and prophylactic vaccines available.
\end{abstract}

Keywords: HPV. Human papilomavírus. Vaccines. Immunological mechanisms. Cervix cancer.

\section{Introdução}

O vírus do papiloma humano (HPV-human papiloma virus) é uma das infecções de transmissão sexual mais freqüente no mundo (CASTROVÁSQUEZ; ARELLANO-GÁLVEZ, 2010). A proporção de pessoas infectadas varia de acordo com as populações e regiões pesquisadas. Estudos mostram que a infecção viral acomete principalmente a população feminina na faixa dos 25 anos, e, após essa idade, segue um padrão de linearidade (MARKOWITZ et al., 2007; GIRIANELLI; THULER; SILVA, 2010). Broomall, Reynolds e Jacobson (2010) afirmam que aproximadamente $80 \%$ das mulheres sexualmente ativas serão contaminadas com algum tipo de HPV até os 50 anos de idade. É conhecido que aproximadamente $99 \%$ dos casos de câncer do colo do útero têm relação com sorotipos invasivos de HPV (BOSCH et al., 1995; WALBOOMERS et al., 1999). De acordo com o Instituto Nacional do Câncer (INCA, 2010), há 18.430 novos casos de câncer do colo do útero no Brasil, dos quais, 4.800 são vítimas fatais. É o segundo tumor mais frequente na população feminina, atrás apenas do câncer de mama, e a quarta causa de morte de mulheres por câncer no Brasil.

Sousa, Pinheiro e Barroso (2008) realizaram um trabalho com o objetivo de investigar o nível de conhecimento das mulheres sobre o HPV. Por meio da investigação, foi possível perceber que, apesar das inúmeras fontes de informação acerca de doenças sexualmente transmissíveis, algumas mulheres ainda apresentam lacunas em relação ao conhecimento sobre o HPV. Isso porque a doença é pouco comentada quando comparada a outras, como a AIDS. Além da falta de conhecimento, o impacto na vida da pessoa diagnosticada é muito grande, podendo levar a depressão.

O risco e a sintomatologia da infecção pelo HPV são distintos entre os gêneros, nos quais homens são geralmente assintomáticos, e as mulheres podem desenvolver inflamações no trato reprodutivo (CASTRO-VÁSQUEZ; ARELLANO-GÁLVEZ, 2010). Ainda que a maioria das infecções siga um curso benigno e se resolva espontaneamente, a infecção persistente, por certos sorotipos de HPV, está associada com o desenvolvimento de cânceres (PIQUÉ; JOSÉ, 2008). Dentre estes, incluem-se os de cérvix, vagina, vulva, pênis, cavidade oral, pescoço, cabeça e região anal.

O HPV apresenta mais de 150 sorotipos, os quais foram identificados por número de acordo com a ordem de descoberta (DE VILLIERS, 1997). Eles são geralmente agrupados de acordo com sua associação com câncer cervical ou lesões pré-cancerosas e sua seqüência genômica: por exemplo, HPV de baixo 
risco de câncer, mais frequentemente os sorotipos 6 e 11 e HPV com alto risco de câncer (HPV 16, 18, 31, 33, 35, e 45). HPVs de baixo risco são encontrados principalmente em verrugas genitais, enquanto HPVs de alto risco são encontrados em câncer cervical e lesões pré-cancerosas (MUNOZ et al., 2003).

Dos 15 sorotipos de risco elevado, os 16 e 18 representam cerca de $70 \%$ dos casos de câncer de colo uterino e cânceres cervicais (CASTRO-VÁSQUEZ; ARELLANO-GÁLVEZ, 2010). A expressão clínica mais conhecida da infecção pelo HPV é constituída por condilomas ou verrugas genitais, e, em 90\% dos casos, há envolvimento de infecção pelos subtipos HPV 6 e 11, e mais raramente, pelos tipos 16 e 42 . Tem sido relatado que estes sorotipos virais podem ser transmitidos verticalmente durante o parto (PIQUÉ; JOSÉ, 2008). As lesões neoplásicas do trato anogenital, como a neoplasia intraepitelial da vulva, vagina, pênis e ânus, estão frequentemente associadas aos HPVs tipicamente carcinogênicos ou de alto risco oncogênico. No entanto, também podem ocasionalmente estar relacionados aos HPVs benignos ou de baixo risco (PIQUÉ; JOSÉ, 2008).

O desenvolvimento do tumor segue duas condições, sendo a primeira uma infecção persistente e a segunda a integração acidental do DNA viral no genoma do hospedeiro. A infecção persistente na maioria das vezes é assintomática e também implica tolerância, e superar a tolerância é o principal desafio para a eficácia da vacina terapêutica (LEPIQUE; RABACHINI; VILLA, 2009).

Atualmente, os dados procedentes de ensaios clínicos de duas vacinas contra HPV disponíveis - uma bivalente frente aos tipos de HPV 16 e 18 e outra tetravalente, frente aos sorotipos 6, 11, 16 e 18 - demonstram que estas vacinas são seguras, imunogênicas e altamente eficazes na prevenção, não só da infecção persistente pelos tipos inclusos nas vacinas, mas também na prevenção de lesões precursoras de carcinoma invasivo de colo uterino. Ambas as vacinas apresentam evidências de proteção cruzada contra a infecção por sorotipos não incluídos na vacina, mas nenhuma delas possui efeitos terapêuticos (PIQUÉ; JOSÉ, 2008). Portanto, o presente trabalho busca revisar os avanços sobre a infecção pelo HPV, os aspectos imunológicos relacionados à infecção e as vacinas profiláticas disponíveis.

\section{Infecção pelo vírus do papiloma humano}

Cerca de 150 sorotipos identificados expressam um tropismo característico. 1, 4, 5, 8, 41, 48, 60, 63 e 65 são alguns dos sorotipos cutaneotrópicos, encontrados frequentemente em verrugas e lesões cutâneas enquanto os sorotipos $6,11,13,16,18,26$, $30,31,32,33,34,35,39,42,44,45,51,52,53,54$, $55,56,58,59,64,66,67,68,69,70$ e 73 são alguns dos que apresentam tropismo pela mucosa. Eles são encontrados em lesões neoplásicas e cancerosas não só do colo uterino, mas também da vagina, vulva, ânus e pênis e, ocasionalmente, também provocam lesões malignas na cavidade oral, orofaringe, laringe e esôfago. O grupo dos sorotipos 2, 3, 7, 10, 27 , $28,29,40,43,57,61,62$ e 72 são encontrados indistintamente em lesões cutâneas ou mucosas e a associação com lesões malignas está menos estabelecida (PIQUÉ; JOSÉ, 2008).

O HPV é um vírus da família Papillomaviridae, de formato icosaédrico sem envelope, com cerca de $55 \mathrm{~nm}$ de diâmetro e 8.000 pares de base (MATZOW et al., 1998). Apresenta um DNA circular de fita dupla, com oito regiões de leitura aberta e uma região regulatória. Os genes são designados como $\mathrm{E}$ (do inglês Early) ou L (do inglês Late) de acordo com o estágio de diferenciação, na qual são expressos: E1 a E8, no início, e L1 e L2, que são expressos durante os estágios finais da diferenciação. Proteínas iniciais (E) são expressas em baixos níveis e são responsáveis pela manutenção do genoma e proliferação celular (DOORBAR, 2006). Os papilomavírus codificam duas proteínas estruturais do capsídeo: a L1 e a L2. A L1 é a proteína maior, da qual cada partícula tem 360 cópias, e sua estrutura ocorre em pentâmeros. A L2 é a menor e cada partícula tem 12 cópias e localiza-se 
no centro do pêntamero formado pelas proteínas L1 (NADAL; MANZIONE, 2006).

A infecção inicial por HPV provavelmente ocorre em células-tronco epiteliais, ou em células que estão transitoriamente se dividindo, localizadas nas camadas mais baixas do epitélio estratificado. À medida que as células mais profundas do epitélio vão se dividindo, elas migram da camada basal e tornamse gradativamente diferenciadas (SILVA; AMARAL; CRUZ, 2002). Com a diferenciação das células epiteliais basais, o vírus amplifica seu material genético e libera novos vírions com concomitante mudança de padrão da expressão gênica, uma vez que são as proteínas L1 e L2 que montam o capsídeo. L1 é a principal proteína do capsídeo, enquanto L2 é de ligação ao DNA viral e facilita o transporte da proteína L1 para o núcleo da célula (DOORBAR, 2006).

A região do HPV de 500 a 1.000 pares de base localizados entre L1 e E6, denominada LCR (região longa de controle) é regulada tanto pelo produto do gene E2, como por outras proteínas celulares (SILVA; AMARAL; CRUZ, 2002). Nas lesões benignas, a replicação viral é extracromossomal, ou seja, os papilomavírus infectam o epitélio e ficam contidos na camada basal das células como estruturas extracromossômicas, que se replicam durante as etapas de multiplicação dos cromossomos. O ciclo de vida do vírus não causa citólise; as partículas virais infecciosas são geradas nas camadas epiteliais mais externas e, a medida que estas começam a se diferenciar, os vírions são eliminados após morte celular sem inflamação (LEPIQUE; RABACHINI; VILLA, 2009).

Entretanto, nas lesões malignas, o DNA viral é integrado aos cromossomos das células do hospedeiro (LETO et al., 2011; RAMIREZ-SALAZAR et al., 2011). Como a inserção do genoma viral no DNA do hospedeiro se dá através da linearização do DNA circular do vírus, há perda do gene E2, e conseqüentemente, ocorre uma superexpressão dos genes virais, como o E6 e E7, responsáveis por estimular a proliferação e transformação celular (SILVA; AMARAL; CRUZ, 2002).

\section{Mecanismos moleculares da carcinogênese cervical pelo papiloma vírus humano de alto risco}

A maior prevalência de HPV é observada em mulheres sexualmente ativas com idade inferior a 25 . O HPV genital é encontrado em aproximadamente $10-40 \%$ dessas mulheres. A maioria dessas infecções parece ser auto-limitada e não está associada com alterações citológicas detectáveis pela triagem do Papanicolaou. Uma minoria de mulheres que apresentam diagnóstico positivo para HPV desenvolvem alterações citológicas de baixo grau (SCHIFFMAN, 1992; DE VILLIERS et al.,1992). A maior incidência de lesões de alto grau ocorre em mulheres com mais de 25 anos de idade (SCHIFFMAN, 1992). Esses achados sugerem que HPV de alto risco, normalmente produz uma infecção inaparente transitória na área cérvico-vaginal. Algumas mulheres desenvolvem uma infecção persistente nesse tecido, talvez como resultado de um mecanismo de defesa deficiente. Lesões persistentes podem progredir para câncer cervical nessas mulheres.

O teste do Papanicolau é um teste de rotina inicialmente introduzido aos serviços clínicos por George N. Papanicolau, em 1939. Esse teste envolve a coleta de células esfoliadas do colo do útero e exame microscópico destas células após coloração e permite detectar células anormais e, assim, estimar se existe risco de haver lesão precursora não detectável clinicamente (SYRJANEN et al., 2005). As alterações celulares benignas incluem inflamação, reparação, metaplasia escamosa imatura, atrofia com inflamação, radiação e outras. É importante notar que a metaplasia somente é considerada quando imatura, pois a metaplasia madura já tem sua diferenciação escamosa definida. As atipias celulares, tanto de células escamosas como de células glandulares, merecem especial atenção, pois incluem atipias 
celulares de significado indeterminado, lesão intraepitelial de baixo grau, lesão intra-epitelial de alto grau, lesão intra-epitelial de alto grau não podendo excluir micro-invasão, carcinoma epidermóide invasor, adenocarcinoma in situ, adenocarcinoma invasor e outras neoplasias (DERCHAIN; LONGATTO FILHO; SYRJANEN, 2005). Esse teste também é conhecido por ter contribuído no controle do desenvolvimento do câncer cervical invasivo através da detecção e o tratamento da neoplasia cervical intraepitelial (ADDIS; HATCH; BEREK, 2006).

HPV16 e HPV18 são os dois tipos de HPV altamente carcinogênicos, sendo responsáveis por $70 \%$ do câncer cervical e aproximadamente $50 \%$ da neoplasia intraepitelial cervical (NIC3) (SMITH et al., 2007); em contraste, HPV6 e HPV11 são responsáveis por aproximadamente 90\% das verrugas genitais (SCHIFFMAN et al., 2007). O câncer de colo do útero caracteriza-se pela replicação desordenada do epitélio de revestimento do órgão, com conseqüente comprometimento do tecido subjacente, o estroma, e possível invasão de estruturas e órgãos próximos ou à distância. Tratase de uma doença de desenvolvimento lento, com fase inicial assintomática quadros de sangramento vaginal intermitente ou após a relação sexual, secreção vaginal anormal e dor abdominal associada com queixas urinárias ou intestinais nos casos mais avançados da doença (INCA, 2010).

Os subtipos HPV16 e HPV18 têm sido bem caracterizados como agentes causadores do câncer cervical. O DNA viral de um grupo de HPV pode ser detectado em $90 \%$ de todos os tipos de cânceres cervicais e, dois genes virais, E6 e E7, são invariavelmente expressos em células de câncer cervical de pacientes HPV-positivos (YUGAWA; KIYONO, 2009; LETO et al., 2011). E6 e E7 são as primeiras proteínas oncogênicas do vírus HPV. Cada uma delas tem vários alvos celulares (MUNGER et al., 2001; MANTOVANI; BANKS, 2001), e os mais importantes são os supressores tumorais p53 e pRB. A proteína E6 inibe p53 e dessa forma bloqueia a apoptose enquanto que a inibição da proteína retinoblastoma ( $\mathrm{pRB}$ ) pela proteína E7 impede a parada do ciclo celular (SCHIFFMAN et al., 2007).

A proteína E6 também apresenta função na ativação da telomerase, e juntamente com a proteína E7 coopera para a imortalização das células epiteliais humanas. Apesar da expressão de E6 e E7 sozinhas não serem suficientes para o desenvolvimento do câncer, essas proteínas parecem estar indireta ou diretamente envolvida em cada estágio da carcinogênese. Estudos epidemiológicos e biológicos sugerem a eficácia das vacinas profiláticas para prevenir a infecção genital por HPV como uma estratégia anti-câncer (YUGAWA; KIYONO, 2009; LETO et al., 2011).

Os oncogenes E6 e E7 são expressos devido à inativação da expressão da proteína E2, promovendo imortalização da célula através da inibição de proteínas celulares que regulam o ciclo celular - p53 e pRB, que são críticas para a supressão do tumor (LETO et al., 2011; RAMIREZ-SALAZAR et al., 2011). A expressão desregulada de E6 e E7 pode, ainda, trazer consequências biológicas, como instabilidade genômica, que aumenta o risco de acúmulo de mudanças genéticas celulares e epigenéticas (YUGAWA; KIYONO, 2009). O vírus se instala na célula e por meio da expressão das oncoproteínas E6 e E7 leva à inibição de proteínas como a p53 e a pRB, importantes no processo de apoptose e parada de ciclo, caracterizando a préformação de lesões cancerosas (Figura 1).

Figura 1 - Mecanismos carcinogênicos do HPV.

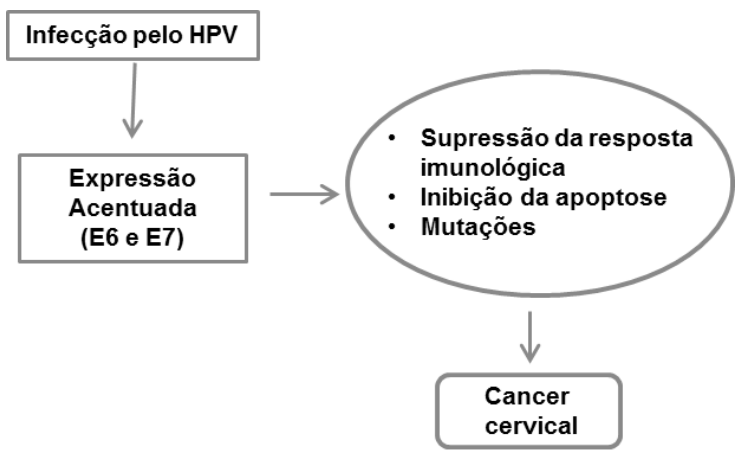

Fonte: Adaptado de YUGAWA e KIYONO (2009). 


\section{Aspectos imunológicos da infecção pelo HPV}

Estudos têm demonstrado que no trato genital feminino há um microambiente imunológico que pode ser modificado por hormônios, bem como por infecções e processos inflamatórios (PUDNEY; QUAYLE; ANDERSON, 2005). No epitélio estratificado escamoso, os queratinócitos indiferenciados que estão localizados nas camadas basais são os primeiros alvos para infecção do HPV (DOORBAR, 2006). Nessas células, a imunidade inataatua como primeira linha de defesa contra os vírus invasores uma vez que elas expressam receptores de reconhecimento de patógenos, incluindo TLR9 que pode se ligar ao DNA viral (HASAN et al., 2007), e TLR3, que reconhece RNA simples fita e dupla fita (KALALI et al., 2008). A ligação a esses receptores de reconhecimento de patógenos levam a ativação direta de NFk-B, resultando na superexpressão de citocinas pró-inflamatórias, e/ou ativação do genes de resposta interferon tipo 1 , incluindo fatores de transcrição que regulam a produção de citocinas antivirais (KOLLISCH et al., 2005; ANDERSEN; AL-KHAIRY; INGALLS, 2006; LEBRE et al., 2007).

A imunidade humoral no trato genital feminino é mediada pela ação das imunoglobulinas IgA e IgG secretadas em abundância na lâmina própria da endocérvice e em escassez na vagina (COHEN; ANDERSON, 1999). Estes anticorpos atuam contra frações antigênicas que são encontradas no muco cervical de pacientes com neoplasia cervical (DILLNER et al., 1989; DILLNER et al., 1993). Entretanto, ao contrário da resposta humoral do pulmão e intestino, há um predomínio de IgG ao invés da IgA no trato genital (JOHANSSON; LYCKE, 2003).

Infiltrado inflamatório composto de macrófagos e células $\mathrm{T}$ CD4+ é observado em condilomas que regridem espontaneamente, e a resposta linfoproliferativa de células T CD4+ específica para o antígeno E2 demonstrou-se associada à eliminação do HPV. Por outro lado, células T CD8+ específicas para os antígenos E6 e E7 são encontradas em pacientes com grandes lesões ou com tumor cervical. Além disso, a diminuição da resposta tipo Th1 com baixa produção de IL-2, IFN- $\gamma$ e TNF- $\alpha$ é observada em pacientes com lesão intraepitelial de alto grau (LEE et al., 2004).

Tem sido evidenciado que uma subpopulação de células $T$, denominada células $T$ regulatórias (Tregs), apresenta envolvimento com tolerância a antígenos próprios. O Foxp3 (Forkhead box p3) está expresso nas células Tregs CD4+CD25+ e tem sido considerado um dos principais mediadores da supressão de tolerância periférica. As Tregs desempenham papel fundamental na limitação da imunopatogênese das infecções virais crônicas de estimulação imune persistente (SAKAGUCHI, 2003).

Foi verificado que mulheres assintomáticas com DNA de HPV apresentam resposta Th1 contra os antígenos do HPV enquanto as Tregs foram encontradas em mulheres com câncer. Os linfócitos de mulheres assintomáticas secretaram INF- $\gamma$, TNF, IL-2, IL-5 e IL-10 em resposta aos antígenos do HPV. No entanto, linfócitos de mulheres com tumor tinham respostas muito fracas e secretaram apenas IL-10 em resposta aos mesmos antígenos (DE JONG et al., 2004). A IL-10 é uma citocina indutora do fenótipo regulador das células T (NIEDERKORN, 2008; POGGI; ZOCCHI, 2008; WAN; FLAVELL, 2008). O TGF- $\beta$ é secretado no ambiente tumoral, apesar de não haver nenhum consenso sobre os níveis de expressão na literatura (KIRMA et al., 2007; DIAZ-CHAVEZ et al.,2008).

A ativação do sistema imunológico tem papel fundamental na defesa contra agentes infecciosos e se constitui no principal impedimento para a ocorrência de infecções disseminadas e, no caso da infecção pelo HPV, ao desenvolvimento do câncer. $\mathrm{Na}$ década passada, iniciaram-se os testes clínicos com várias vacinas que tinham como alvo os sorotipos mais comuns do HPV. As vacinas profiláticas evitam a infecção pelo HPV e suas doenças associadas e 
as terapêuticas induzem a regressão das lesões précancerosas e a remissão do câncer invasivo.

\section{Vacinas profiláticas contra a infecção por HPV}

Sabe-se que o vírus do HPV infecta células basais epiteliais da mucosa ou da pele (CUTTS et al., 2007). A infecção genital é transmitida principalmente pelo contato genital pele com pele, e não necessariamente durante a penetração (KJAER et al., 2001; MUNOZ et al., 2004; CASTLE et al., 2005). Portanto, o uso de preservativo não oferece uma proteção $100 \%$ eficaz (CARTER et al., 2000). Apesar das infecções, na grande maioria, não apresentarem sintomas e serem limitadas, a infecção por HPV genital persistente pode causar câncer cervical nas mulheres e outros tipos de cânceres e verrugas anogenitais, tanto em homens quanto em mulheres (MARKOWITZ et al., 2007).

As vacinas profiláticas evitam a infecção pelo HPV e suas doenças associadas e as terapêuticas induzem a regressão das lesões pré-cancerosas e a remissão do câncer invasivo. As primeiras foram compostas pela proteína capsídeo L1 do HPV que se auto-reproduz em partículas virus-like (VLP- Virus Like Particles) quando expressa em sistemas recombinantes, induzindo forte resposta humoral com anticorpos neutralizadores (NADAL; MANZIONE, 2006).

Os VLPs são expostos ao sistema imunológico (por meio de imunização) e vem demonstrando capacidade de induzir títulos elevados de anticorpos neutralizantes em modelos animais e também em humanos (PIQUÉ; JOSÉ, 2008). Um mês após a terceira dose da vacina de HPV, aproximadamente $100 \%$ das mulheres com idade entre 15 e 26 anos têm anticorpos detectáveis para cada genótipo HPV, com os níveis sendo de 10 a 104 vezes maior do que nas infecções naturais (HARPER et al., 2004; HARPER et al., 2006; VILLA et al., 2006).

Atualmente, existem duas vacinas profiláticas contra o HPV comercializadas. Elas previnem muitas infecções pelo vírus, reduzindo assim o risco de doenças associadas ao HPV (LEPIQUE; RABACHINI; VILLA, 2009; PIQUÉ; JOSÉ, 2008).

A vacina bivalente, composta de VLP de HPV tipos 16 e 18, e apresenta proteção contra infecção incidente ou persistente pelos sorotipos inclusos na vacina e também previne as lesões neoplásicas cervicais relacionadas aos mesmos. Já a vacina tetravalente apresenta VLP de HPV dos tipos 6, 11, 16 e 18, conferindo proteção à infecção e lesões citadas acima, assim como prevenção de verrugas genitais e lesões vulvares e vaginais (CUTTS et al., 2007; PIQUÉ; JOSÉ, 2008). Castellsagué et al. (2011) demonstraram que a vacina tetravalente dos sorotipo, 6, 11, 16 e 18 recombinante apresentou imunogenicidade e eficácia em mulheres com 24 a 45 anos de idade.

Ainda que a maioria das vacinas antivirais se baseiem no uso de vírus para induzir anticorpos antivirais, é difícil produzir quantidades suficientes de vírus HPV em cultivos celulares para induzir uma resposta adequada no hospedeiro. Além disso, como os vírus HPV contêm DNA oncogênico, o uso de vírus HPV atenuado é considerado uma estratégia de alto risco para o desenvolvimento da vacina de HPV (PIQUÉ et al., 2006).

A injeção intramuscular da VLP resulta em resposta imune adaptativa eficaz para células $\mathrm{T}$ e $\mathrm{B}$, que são capazes de neutralizar as infecções naturais subseqüentes. A vacina HPV16 L1 VLP determinou índice elevado de proteção contra a infecção persistente pelo HPV 16 e a bivalente demonstrou mesma eficácia (HARPER et al., 2006).

Embora as vacinas tenham surgido como um grande avanço na prevenção contra a infecção pelo HPV, muito há para ser discutido sobre o custo e efetividade (HUTUBESSY et al., 2011). E apesar da não disponibilidade desta vacina na rotina, esperase que em um futuro próximo, a mesma esteja disponível a todas as classes sociais, tanto para o público leigo como para os profissionais de saúde. 


\section{Referências}

ADDIS, I. B.; HATCH, K. D.; BEREK, J. S. Intraepithelial disease of the cervix, vagina and vulva. In: BEREK, J. S. Berek \& Novak's gynecology. 14. ed. Philadelphia: Lippincott Williams \& Wilkins, 2006. p. 561-599.

ANDERSEN, J. M.; AL-KHAIRY, D.; INGALLS, R. R. Innate immunity at the mucosal surface: role of toll-like receptor 3 and toll-like receptor 9 in cervical epithelial cell responses to microbial pathogens. Biology Reproduction, Madison, v. 74, p. 824-831, 2006.

BOSCH, F. X.; MANOS, M.; MUÑOZ, N.; SHERMAN, M.; JANSEN, A.; PETO, J.; SCHIFFMAN, M. H.; MORENO, V.; KURMAN, R.; SHAN, K. V. Prevalence of human papillomavirus in cervical cancer: a worldwide perspective. National Cancer Institute, Bethesda, v. 87, p. 796-802, 1995.

BROOMALL, E. M.; REYNOLDS, S. M., JACOBSON, R. M. Epidemiology, clinical manifestations, and recent advances in vaccination against human papillomavirus. Postgraduate Medicine, Berwyn, v. 122, n. 2, p. 121-129, 2010.

CARTER, J. J.; KOUTSKY, L. A.; HUGHES, J. P.; LEE, S. K.; KUYPERS, J.; KIVIAT, N.; GALLOWAY, D. A. Comparison of human papillomavirus types 16,18 , and 6 capsid antibody responses following incident infection. Journal of Infectious Disease, Chicago, v. 181, p. 19111919, 2000.

CASTELLSAGUÉ, X.; MUÑOZ, N.; PITISUTTITHUM, P.; FERRIS, D.; MONSONEGO, J.; AULT, K.; LUNA, J.; MYERS, E.; MALLARY, S.; BAUTISTA, O. M.; BRYAN, J.; VUOCOLO, S.; HAUPT, R. M.; SAAH, A. End-of-study safety, immunogenicity, and efficacy of quadrivalent HPV (types $6,11,16,18$ ) recombinant vaccine in adult women 24-45 years of age. British Journal of Cancer, London, v. 105, n. 1, p. 28-37, 2011.

CASTLE, P. E.; SCHIFFMAN, M.; HERRERO, R.; HILDESHEIM, A.; RODRIGUEZ, A. C.; BRATTI, M. C.; SHERMAN, M. E.; WACHOLDER, S.; TARONE, R.; BURK, R. D. A prospective study of age trends in cervical human papillomavirus acquisition and persistence in Guanacaste, Costa Rica. Journal of Infectious Disease, Chicago, v. 191, p. 1808-1816, 2005.

CASTRO-VÁSQUEZ, M. C.; ARELLANO-GÁlVEZ, M. C. Acceso a La información de mujeres con VPH, displasia y câncer cervical in situ. Salud Pública de México, Cuernavaca, v. 52, p. 207-212, 2010.

COHEN, M. S.; ANDERSON, D. J. Genitourinary mucosal defenses. In: HOLMES, K. K.; SPARLING, T. F.; MARDH, P. A.; LEMOY, S. M. Sexually transmitted diseases. New York: McGraw-Hill, 1999. p. 173-190.

CUTTS, F. T.; FRANCESCHI, S.; GOLDIE, S.; CASTELLSAGUE, X.; DE SANJOSE, S.; GARNETT, G.; EDMUNDS, W. J.; CLAEYS, P.; GOLDENTHAL, K. L.; HARPER, D. M.; MARKOWITZ, L. Human papillomavirus and HPV vaccines: a review. Bulletin of the World Health Organization, Geneva, v. 85, n. 9, p. 719-726, 2007.

DE JONG, A.; VAN POELGEEST, M. I.; VAN DER HULST, J. M.; DRIJFHOUT, J. W.; FLEUREN, G. J.; MELIEF, C. J.; KENTER, G.; OFFRINGA, R.; VAN DER BURG, S. H. Human papillomavirus type 16-positive cervical cancer is associated with impaired CD4+ T-cell immunity against early antigens E2 and E6. Cancer Research, Baltimore, v. 64, p. 5449-5455, 2004.

DERCHAIN, S. F. M.; LONGATTO FILHO, A.; SYRJANEN, K. J. Neoplasia intra-epitelial cervical: diagnóstico e tratamento. Revista Brasileira de Ginecologia \& Obstetrícia, Rio de Janeiro, v. 27, n. 7, p. 425-433, 2005.

DIAZ-CHAVEZ, J.; HERNANDEZ-PANDO, R.; LAMBERT, P. F.; GARIGLIO, P. Down-regulation of transforming growth factor- $\beta$ type II receptor (TGF$\beta R I I)$ protein and mRNA expression in cervical cancer. Molecular Cancer, London, v. 7, p. 3-14, 2008.

DILLNER, L.; BEKASSY, Z.; JONSSON, N.; MORENO-LOPEZ, J.; BLOMBERG, J. Detection of IgA antibodies against human papillomavirus in cervical secretions from patients with cervical intraepithelial neoplasia. International Journal of Cancer, New York, v. 43, p. 36-40, 1989.

DILLNER, L.; FREDRIKSSON, A.; PERSSON, E.; FORSLUND, O.; HANSSON, B. G.; DILLNER, J. Antibodies against papillomavirus antigens in cervical secretions from condyloma patients. Journal of Clinical Microbiology, Washington, v. 31, p. 192-197, 1993.

DOORBAR, J. Molecular biology of human papillomavirus infection and cervical cancer. Clinical Science, London, v. 110, p. 525-541, 2006.

GIRIANELLI, V. R.; THULER, L. C. S.; SILVA, G. A. Prevalence of HPV infection among women covered by the family health program in the Baixada Fluminense, Rio de Janeiro, Brazil, 2010. Revista Brasileira de Ginecologia e Obstetrícia, Rio de Janeiro, v. 32, n. 1, p. 39-46, 2010. 
HARPER, D. M.; FRANCO, E. L.; WHEELER, C.; FERRIS, D. G.; JENKINS, D.; SCHUIND, A.; ZAHAF, T.; INNIS, B.; NAUD, P.; DE CARVALHO, N. S.; ROTELI-MARTINS, C. M.; TEIXEIRA, J.; BLATTER, M. M.; KORN, A. P.; QUINT, W.; DUBIN, G. Efficacy of a bivalent $\mathrm{L} 1$ virus-like particle vaccine in prevention of infection with human papillomavirus types 16 and 18 in young women: a randomized controlled trial. The Lancet, London, v. 364, p. 1757-1765, 2004.

HARPER, D. M.; FRANCO, E. L.; WHEELER, C. M.; MOSCICKI, A. B.; ROMANOWSKI, B.; ROTELIMARTINS, C. M.; JENKINS, D.; SCHUIND, A.; COSTA CLEMENS, S. A.; DUBIN, G. Sustained efficacy up to 4.5 years of a bivalent $\mathrm{L} 1$ virus-like particle vaccine against human papillomavirus types 16 and 18: follow-up from a randomised control trial. The Lancet, London, v. 367, p. 1247-1255, 2006.

HASAN, U. A.; BATES, E.; TAKESHITA, F.; BILIATO, A.; ACCARDI, R.; BOUVARD, V.; MANSOUR, M.; VINCENT, I.; GISSMANN, L.; IFTNER, T.; SIDERI, M.; STUBENRAUCH, F.; TOMMASINO, M. TLR9 expression and function is abolished by the cervical cancer-associated human papillomavirus type 16. Journal of Immunology, Bethesda, v. 178, p. 3186-3197, 2007.

HUTUBESSY, R.; HENAO, A. M.; NAMGYAL, P.; MOORTHY, V.; HOMBACH, J. Results from evaluations of models and cost-effectiveness tools to support introduction decisions for new vaccines need critical appraisal. BMC Medicine, London, v. 9, n. 1, p. 55, 2011.

INSTITUTO NACIONAL DO CÂNCER - INCA. Câncer tipo colo do útero. 2010. Disponível em: $<$ http:// www2.inca.gov.br/wps/wcm/connect/tiposdecancer/site/ home/colo_utero/definicao>. Acesso em: 4 jun. 2011.

JOHANSSON, M.; LYCKE, N. Y. Immunology of the human genital tract. Current Opinion in Infectious Disease, Hagerstown, v. 16, p. 43-49, 2003.

KALALI, B. N.; KOLLISCH, G.; MAGES, J.; MULLER, T.; BAUER, S.; WAGNER, H.; RING, J.; LANG, R.; MEMPEL, M.; OLLERT, M. Doublestranded RNA induces an antiviral defense status in epidermal keratinocytes through TLR3-, PKR-, and MDA5/RIG-Imediated differential signaling. Journal of Immunology, Bethesda, v. 181, p. 2694-2704, 2008.

KIRMA, N.; HAMMES, L. S.; LIU, Y.; NAIR, H. B.; VALENTE, P. T.; KUMAR, S.; FLOWERS, L. C.; TEKMAL, R. R. Elevated expression of the oncogene c-fms and its ligand, the macrophage colony-stimulating factor-1, in cervical cancer and the role of transforming growth factor- $\beta 1$ in inducing C-FMS expression. Cancer
Research, Baltimore, v. 67, p. 1918-1926, 2007.

KJAER, S. K.; CHACKERIAN, B.; VAN DEN BRULE, A. J.; SVARE, E. I.; PAULL, G.; WALBOMERS, J. M.; SCHILlER, J. T.; BOCK, J. E.; SHERMAN, M. E.; LOWY, D. R.; MEIJER, C. L. High-risk human papillomavirus is sexually transmitted: evidence from a follow-up study of virgins starting sexual activity (intercourse). Cancer Epidemiology Biomarkers \& Prevention, Philadelphia, v. 10, p. 101-106, 2001.

KOLLISCH, G.; KALAL, I. B. N.; VOELCKER, V.; WALLICH, R.; BEHRENDT, H.; RING, J.; BAUER, S.; JAKOB, T.; MEMPEL, M.; OLLERT, M. Various members of the Toll-like receptor family contribute to the innate immune response of human epidermal keratinocytes. Immunology, Oxford, v. 114, p. 531-541, 2005 .

LEBRE, M. C.; VAN DER AAR, A. M.; VAN BAARSEN, L.; VAN CAPEL, T. M.; SCHUITEMAKER, J. H.; KAPSENBERG, M. L.; DE JONG, E. C. Human keratinocytes express functional Toll-like receptor 3, 4, 5, and 9. The Journal of Investigative Dermatology, New York, v. 127, p. 331-341, 2007.

LEE, B. N.; FOLLEN, M.; SHEN, D. Y.; MALPICA, A.; ADLER-STORTHZ, K.; SHEARER, W. T.; REUBEN, J. M. Depressed type 1 cytokine synthesis by superantigen-activated CD4+ T cells of women with human papillomavirus-related high-grade squamous intraepithelial lesions. Clinical and Diagnostic Laboratory Immunology, Washington, v. 11, p. 239-244, 2004.

LEPIQUE, A. P.; RABACHINI, T.; VILLA, L. L. HPV vaccination: the beginning of the end of cervical cancer? A Review. Memórias do Instituto Oswaldo Cruz, Rio de Janeiro, v. 104, p. 1-10, 2009.

LETO, M. G. P.; SANTOS JUNIOR, G. F.; TOMIMORI, A. M. P.; TOMIMORI, J. Human papillomavirus infection: etiopathogenesis, molecular biology and clinical manifestations. Anais Brasileiros de Dermatologia, Rio de Janeiro, v. 86, n. 2, p. 306-317, 2011.

MANTOVANI, F.; BANKS, L. The human papillomavirus E6 protein and its contribution to malignant progression. Oncogene, Basingstoke, v. 20, p. 7874-7887, 2001.

MARKOWITZ, L. E.; DUNNE, E. F.; SARAIYA, M.; LAWSON, H. W.; CHESSON, H.; UNGER, E. R. Quadrivalent Human Papillomavirus Vaccine Recommendations of the Advisory Committee on Immunization Practices (ACIP). MMWR Recommendations and Reports, Atlanta, v. 56, n. RR-2, 2007. 
MATZOW, T.; BOYSEN, M.; KALANTARI, M.; JOHANSSON, B.; HAGMAR, B. Low detection rate of HPV in oral and laryngeal carcinomas. Acta Oncologica, London, v. 37, n. 1, p. 73-76, 1998.

MUNGER, K.; BASILE, J. R.; DUENSING, S.; EICHTEN, A.; GONZALEZ, S. L.; GRACE, M.; ZACNY, V. L. Biological activities and molecular targets of the human papillomavirus E7 oncoprotein. Oncogene, Basingstoke, v. 20, p. 7888-7898, 2001.

MUNOZ, N.; BOSCH, F. X.; DE SANJOSE, S.; HERRERO, R.; CASTEllSAGUÉ, X.; SHAH, K. V.; SNIJDERS, P. J.; MEIJER, C. J. Epidemiologic classification of human papillomavirus types associated with cervical cancer. The New England Journal of Medicine, Boston, v. 348, p. 518-527, 2003.

MUNOZ, N.; MENDEZ, F.; POSSO, H.; MOLANO, M.; VAN DEN BRULE, A. J.; RONDEROS, M.; MEIJER, C.; MUÑOZ A. Incidence, duration, and determinants of cervical human papillomavirus infection in a cohort of Colombian women with normal cytological results. Journal of Infectious Disease, Chicago, v. 190, p. 20772087, 2004.

NADAL, S. D.; MANZIONE, C. R. Vacinas contra o papilomavirus humano. Revista Brasileira de Coloproctologia, Rio de Janeiro, v. 26, n. 3, p. 337-340, 2006.

NIEDERKORN, J. Y.; Emerging cocepts in CD8+ $\mathrm{T}$ regulatory cells. Current Opinion in Immunology, London, v. 20, n. 3, p. 327-331, 2008.

PIQUÉ, X. C.; ABRIL, G. A.; CARDONA, D. M.; FARNÓS, M. J. P.; ORTEGA, P. F.; FAVA, C. B.; MASDEU, M. S.; ARSEDA, M. D.; FORNELLS, E. R.; JOSÉ, F. X. B. Prevención primaria: vacunas frente al virus del papiloma humano (VPH) para la prevención del cáncer de cuello uterino. Cap. 6. 2006. In: LLONGUERAS, S. de S.; GARCÍA, A. M. G. (Ed.). Virus del papiloma humano y cáncer: epidemiología y prevención. 2006. Cap. 6. Disponível em: <http://www. seepidemiologia.es/documents/dummy/4monografiaViru sPapilomaYCancer.pdf $>$. Acesso em: 4 jun. 2011.

PIQUÉ, X. C.; JOSÉ, F. X. Vacunas frente al vírus del papiloma humano. Enfermedades Infecciosas y Microbiología Clínica, Barcelona, v. 26, n. 1, p. 65-77, 2008.

POGGI, A.; ZOCCHI, R. M. Role of bone marrow stromal cells in the generation of human CD8+ regulatory T cells. Human Immunology, New York, v. 69, n. 11, p. 755-759, Nov. 2008.
PUDNEY, J.; QUAYLE, A. J.; ANDERSON, D. J. Immunological microenvironments in human vagina and cervix: mediators of cellular immunity are concentrated in the cervical transformation zone. Biology of Reproduction, Madison, p. 1253-1263, 2005.

RAMIREZ-SALAZAR, E. R.; CENTENO, F.; NIETO, K.; HERNÁNDEZ, A. V.; SALCEDO, M.; GARRIDO, E. HPV16 E2 could act as down-regulator in cellular genes implicated in apoptosis, proliferation and cell differentiation. Virology Journal, London, v. 8, p. 247, 2011.

SAKAGUCHI, S. Regulatory $\mathrm{T}$ cells: mediating compromises between host and parasite. Nature Immunology, New York, v. 4, n. 1, p. 10-11, 2003.

SCHIFFMAN, M.; CASTLE, P. E.; JERONIMO, J.; RODRIGUEZ, A. C.; WACHOLDER, S. Human papillomavirus and cervical cancer. The Lancet, London, v. 370, n. 9590, p. 890-907, 2007.

SCHIFFMAN, M. H. Recent progress in defining the epidemiology of human papillomavirus infection and cervical neoplasia. Journal of the National Cancer Institute, Carry, v. 84, p. 394-398, 1992.

SILVA, A. M. T. C.; AMARAL, M. V. T.; CRUZ, A. D. C. HPV e câncer: o papel do Papiloma vírus humano na carcinogênese. Biotecnologia Ciência e Desenvolvimento, Brasília, v. 29, p. 48-54, 2002.

SMITH, J. S.; LINDSAY, L.; HOOTS, B.; KEYS, J.; FRANCESCHI, S.; WINER, R.; CLIFFORD, G. M. Human papillomavirus type distribution in invasive cervical cancer and high-grade cervical lesions: a metaanalysis update. International Journal of Cancer, New York, v. 121, p. 621-632, 2007.

SOUSA, L. B.; PINHEIRO, A. K. B.; BARROSO, M. G. T. Ser mulher portadora do HPV: uma abordagem cultural. Revista da Escola de Enfermagem USP, São Paulo, v. 42, n. 4, p. 737-743, 2008.

SYRJÄNEN, K.; NAUD, P.; DERCHAIN, S.; ROTELIMARTINS, C.; LONGATTO-FILHO, A.; TATTI, S.; BRANCA, M.; ERZEN, M.; HAMMES, L. S.; MATOS, J.; GONTIJO, R.; SARIAN, L.; BRAGANCA, J.; ARLINDO, F. C.; MAEDA, M. Y.; LÖRINCZ, A.; DORES, G. B.; COSTA, S.; SYRJÄNEN, S. Comparing PAP smear cytology, aided visual inspection, screening colposcopy, cervicography and HPV testing as optional screening tools in Latin America study design and baseline data for the LAMS study. Anticancer Research, Attiki, v. 25, n. 5, p. 3469-80, 2005. 
VILLA, L. L.; AULT, K. A.; GIULIANO, A. R.; COSTA, R. L.; PETTA, C. A.; ANDRADE, R. P.; BROWN, D. R.; FERENCZY, A.; HARPER, D. M.; KOUTSKY, L. A.; KURMAN, R. J.; LEHTINEN, M.; MALM, C.; OLSSON, S. E.; RONNETT, B. M.; SKJELDESTAD, F. E.; STEINWALL, M.; STOLER, M. H.; WHEELER, C. M.; TADDEO, F. J.; YU, J.; LUPINACCI, L.; RAILKAR, R.; MARCHESE, R.; ESSER, M. T.; BRYAN, J.; JANSEN, K. U.; SINGS, H. L.; TAMMS, G. M.; SAAH, A. J.; BARR, E. Immunologic responses following administration of a vaccine targeting human papillomavirus types $6,11,16$, and 18. Vaccine, Amsterdam, v. 24, p. 5571-5583, 2006.

DE VILLIERS EM. Papillomavirus and HPV typing. Clin Dermatol. 1997;15:199-206.

DE VILLIERS EM. Laboratory techniques in the investigation of human papillomavirus infection. Genitourin Med. 1992 Feb;68(1):50-4

WALBOOMERS, J. M.; JACOBS, M. V.; MANOS, M. M.; BOSCH, F. X.; KUMMER, J. A.; SHAH, K. V.; SNIJDERS, P. J.; PETO, J.; MEIJER, C. J.; MUÑOZ, N. Human papillomavirus is a necessary cause of invasive cervical cancer worldwide. The Journal of Pathology, Chichester, v. 189, p. 12-19, 1999.

WAN, Y. Y.; FLAVELL, R. A. TGF-beta and Regulatory $\mathrm{T}$ Cell in Immunity and Autoimmunity. Journal of Clinical Immunology, v. 28, n. 6, p. 647-659, Nov. 2008.

YUGAWA, T.; KIYONO, T. Molecular mechanisms of cervicalcarcinogenesis by high-risk humanpapillomaviruses: novel functions of E6and E7 oncoproteins. Reviews in Medical Virology, Chichester, v. 19, p. 97-113, 2009.

Recebido em 24 de setembro de 2011

Aceito em 03 de fevereiro de 2012 
